\title{
New vineyard cultivation practices create patchy ground vegetation, favouring Woodlarks
}

\author{
Raphaël Arlettaz $\cdot$ Melanie Linda Maurer • \\ Paul Mosimann-Kampe $\cdot$ Sébastien Nusslé $\cdot$ \\ Fitsum Abadi · Veronika Braunisch • Michael Schaub
}

Received: 24 December 2010/Revised: 23 June 2011 / Accepted: 25 July 2011 / Published online: 11 August 2011

(C) Dt. Ornithologen-Gesellschaft e.V. 2011

\begin{abstract}
Intensive agriculture, in which detrimental farming practices lessen food abundance and/or reduce food accessibility for many animal species, has led to a widespread collapse of farmland biodiversity. Vineyards in central and southern Europe are intensively cultivated; though they may still harbour several rare plant and animal species, they remain little studied. Over the past decades, there has been a considerable reduction in the application of insecticides in wine production, with a progressive shift to biological control (integrated production) and, to a lesser extent, organic production. Spraying of herbicides has also diminished, which has led
\end{abstract}

Communicated by T. K. Gottschalk.

Electronic supplementary material The online version of this article (doi:10.1007/s10336-011-0737-7) contains supplementary material, which is available to authorized users.

R. Arlettaz $(\bowtie) \cdot$ M. L. Maurer · P. Mosimann-Kampe .

F. Abadi · V. Braunisch · M. Schaub

Institute of Ecology and Evolution, Division of Conservation

Biology, University of Bern, Baltzerstrasse 6,

3012 Bern, Switzerland

e-mail: Raphael.Arlettaz@iee.unibe.ch

R. Arlettaz $\cdot$ M. Schaub

Swiss Ornithological Institute, 6204 Sempach, Switzerland

S. Nusslé

Department of Ecology and Evolution, Biophore,

University of Lausanne, 1015 Lausanne, Switzerland

F. Abadi

Department of Zoology, Animal Demography Unit,

University of Cape Town, Rondebosch 7701, South Africa to more vegetation cover on the ground, although most vineyards remain bare, especially in southern Europe. The effects of these potentially positive environmental trends upon biodiversity remain mostly unknown as regards vertebrates. The Woodlark (Lullula arborea) is an endangered, short-distance migratory bird that forages and breeds on the ground. In southern Switzerland (Valais), it occurs mostly in vineyards. We used radiotracking and mixed effects logistic regression models to assess Woodlark response to modern vineyard farming practices, study factors driving foraging micro-habitat selection, and determine optimal habitat profile to inform management. The presence of ground vegetation cover was the main factor dictating the selection of foraging locations, with an optimum around 55\% at the foraging patch scale. These conditions are met in integrated production vineyards, but only when grass is tolerated on part of the ground surface, which is the case on ca. 5\% of the total Valais vineyard area. In contrast, conventionally managed vineyards covering $\geq 95 \%$ of the vineyard area are too bare because of systematic application of herbicides all over the ground, whilst the rare organic vineyards usually have a too-dense sward. The optimal mosaic with ca. $50 \%$ ground vegetation cover is currently achieved in integrated production vineyards where herbicide is applied every second row. In organic production, ca. 50\% ground vegetation cover should be promoted, which requires regular mechanical removal of ground vegetation. These measures are likely to benefit general biodiversity in vineyards.

Keywords Agricultural intensification .

Population decline - Herbicides .

Vegetation structure - Lullula arborea .

Habitat selection - Habitat restoration 


\section{Zusammenfassung}

\section{Neue Methoden im Weinbau schaffen lückige Bodenvegetation und fördern die Heidelerche}

Die Intensivlandwirtschaft, deren Anbaumethoden sich vielfach negativ auf die Nahrungsverfügbarkeit für viele Tierarten auswirken, hat zu einem großflächigen Rückgang der Biodiversität in Agrarlebensräumen geführt. In den Weinbaugebieten Zentral- und Südeuropas, die trotz intensiver Bewirtschaftung immer noch viele seltene Tier- und Pflanzenarten beherbergen, sind diese Zusammenhänge bisher nur wenig untersucht. In der Schweiz wurde die Anwendung von Insektiziden während der letzten Jahrzehnte stark reduziert, einhergehend mit einem Trend hin zur Integrierten Produktion (IP; biologische Schädlingskontrolle) und - in geringerem Umfangbiologischer Produktion (Bioweinbau). Auch die Verwendung von Herbiziden wurde eingeschränkt, was zu einer Zunahme der Bodenvegetation führte. Die Auswirkungen dieser potentiell biodiversitätsfördernden Trends auf die Wirbeltierfauna sind jedoch bisher unklar. Die Heidelerche (Lullula arborea), ein gefährdeter Kurz-strecken-zieher, der am Boden sowohl brütet als auch Nahrung sucht, kommt in der Südschweiz (Wallis) vorwiegend in Rebgebieten vor. Mit Hilfe von Radiotelemetrie und gemischten logistischen Regressionsmodellen untersuchten wir die Auswirkungen moderner Wein-anbau-methoden auf die Nahrungshabitatselektion der Heidelerche und bestimmten das optimale Habitatprofil als Grundlage für Managementempfehlungen. Bei der Nahrungssuche wurde die Habitatwahl hauptsächlich durch den Deckungsgrad der Bodenvegetation bestimmt, wobei das Optimum bei 55\% lag. In Rebparzellen, die nach den Vorgaben der IP bewirtschaftet werden, sind diese Bedingungen erfüllt, wenn auf einem Teil der Fläche Grasbewuchs toleriert wird-dies ist jedoch auf weniger als 5\% der gesamten Wein-Anbaufläche im Wallis der Fall. Herkömmlich bewirtschaftete Rebparzellen haben aufgrund der systematischen Anwendung von Herbiziden zuwenig Bodenvegetation, während die wenigen biologisch bewirtschafteten Rebparzellen eine zu dichte Bodenvegetation aufweisen. IP Rebparzellen, bei der eine Anwendung von Herbiziden in jeder zweiten Reihe von Weinstöcken ein alternierendes Muster von bewachsenen und unbewachsenen Reihen hervorbringt, scheinen sich damit vorteilhaft auf die Heidelerche auszuwirken. In biologisch bewirtschafteten Rebparzellen könnte dieser Mosaikeffekt durch eine teilweise, mechanische Entfernung der Bodenvegetation erreicht werden. Diese Maßnahme würde sehr wahrscheinlich auch allgemein zur Biodiversitätsförderung in Weinanbaugebieten beitragen.

\section{Introduction}

Intensive agricultural practices have led to a widespread decline in farmland biodiversity across many different taxa such as plants, arthropods, birds and bats (e.g. Poulsen et al. 1998; Donald et al. 2001; Vickery et al. 2001; Benton et al. 2003; Wickramasinghe et al. 2003; Gregory et al. 2004; Verhulst et al. 2004; Hole et al. 2005; Britschgi et al. 2006). Benton et al. (2002) have established that insect population sizes have in general significantly decreased over time, with invertebrate abundance still remaining higher in low intensity farming. A drastic drop in arthropod abundance has in turn affected the populations of insectivorous vertebrates (Brickle et al. 2000; Benton et al. 2002; Britschgi et al. 2006).

Habitat alteration and agrochemicals are believed to be the main factors of biodiversity reduction in farmland, affecting individual survival and reproductive output (Brickle et al. 2000; Boatman et al. 2004). According to Boatman et al. (2004), pesticides may affect food availability for birds in three ways: (1) arthropod populations could be eliminated or depleted due to insecticides, resulting in reduced breeding success in adults that feed their young with insects; (2) the abundance of non-crop plants which operate as hosts for arthropods may be reduced through herbicide use; (3) herbicides can deplete or eliminate plant species that provide either green matter or seeds for herbivorous and granivorous species. Such effects were demonstrated in two farmland birds, the Skylark Alauda arvensis (Boatman et al. 2004) and the Corn Bunting Milaria calandra (Brickle et al. 2000).

Fertilizers may also affect bird population dynamics through major changes in the structure of ground vegetation cover. A dense sward, for instance, impedes forager's mobility, and diminishes foraging efficiency through lower prey detectability and accessibility (Vickery et al. 2001; Atkinson et al. 2004; Butler and Gillings 2004; Weisshaupt et al. 2011). A mosaic of dense and sparsely vegetated ground is thus likely to provide the maximum benefits for many farmland birds (Benton et al. 2003; McCracken and Tallowin 2004; Schaub et al. 2010). Birds that feed on soil invertebrates typically prefer short grazed swards or patches of bare earth (Atkinson et al. 2004; Martinez et al. 2010; Schaub et al. 2010). Toepfer and Stubbe (2001) showed that skylarks prefer a vegetation cover of $35-60 \%$ and a vegetation height of $25-60 \mathrm{~cm}$. 
In Switzerland, 14,800 ha are devoted to vineyard cultivation, with one-third of the area occurring in Valais (SW Switzerland). Vineyards in Valais are located on the sunexposed foothills slopes, mostly north of the Rhône river, up to $900 \mathrm{~m}$ above sea level. Often organized in successive terraces along the slopes, the vineyards support a variety of different soil types and compositions, and are intermixed with natural elements such as patches of steppe on rocky outcrops, or fragments of xerophilous forests. This allows a great diversity of vines to be grown, as well as the occurrence of rare and specialized plant and animal species (Sierro and Arlettaz 2003). Most of the Valais vineyards are currently cultivated according to the biological control protocol (also called integrated production), which has led to a progressive decline of pesticides utilization over the past 15 years. In addition, a recent trend among these wine producers is to tolerate more vegetation on the ground than in the recent past, when the entire soil surface was systematically sprayed with herbicides (Sierro and Arlettaz 2003). However, restriction of herbicide application is not mandatory in the biological control protocol, which explains why most Valais vineyards ( $\geq 95 \%$, hereafter "conventional vineyards") still have a very "mineral" appearance (the soil matrix is then totally or almost totally visible, being dominated by bare earth, gravels, pebbles and stones). Valais vineyards thus represent a very different situation than what is usually encountered in grassy habitats: here the predominant habitat conditions are not a too-dense cover and sward, unlike in other studies of grassland biodiversity (e.g. Atkinson et al. 2004; Schaub et al. 2010), but a predominantly bare habitat. In contrast, organic cultivation, which remains rare in the study area, is characterized by an almost continous vegetation cover on the ground. Although progressive "greening" of vineyards will certainly be beneficial to biodiversity (most herbivorous invertebrates, for instance), one may fear that a toodense sward will be detrimental for many terrestrial organisms (e.g. some rare southern species of butterflies and acridids which require patches of bare ground to accomplish their life cycle) because it could result in limited accessibility to essential resources such as food and/or nesting opportunities (Atkinson et al. 2004; Schaub et al. 2010).

We used the Woodlark Lullula arborea as a model to test the response of terrestrially-feeding vertebrates to novel vineyard management practices. The Woodlark is partly migratory and mostly insectivorous during the breeding season. Since the middle of the last century, there has been a dramatic decline in the Swiss Woodlark population (Leuzinger 1955; Glutz von Blotzheim and Bauer 1985; Schmid et al. 1998, 2001). At present, ca. 250-300 breeding pairs remain in Switzerland, with about half of them occurring in Valais vineyards (A. Gerber, H. Schmid and A. Sierro, unpublished data). The species is thus classified as vulnerable and belongs to the 50 priority bird species of Switzerland for which action plans are currently under development (Keller et al. 2010a, b). In Europe, it is a species of conservation concern (Burfield and van Bommel 2004).

In order to support efforts to preserve the species in Switzerland, we used radiotracking to investigate its key ecological niche preferences in vineyards, with the goal of drawing optimal habitat profiles that may serve as guidelines for optimizing biodiversity-friendly vineyard management. This information may be useful beyond the study area, since declines of Woodlarks have been reported in most northern and western European countries (Glutz von Blotzheim and Bauer 1985; Snow and Perrins 1998), although there is evidence for recent recoveries in some areas (Langston et al. 2007; Wright et al. 2009). As the Woodlark probably plays the role of an umbrella species within vineyards, other elements of flora and fauna would also benefit from any conservation and restoration measures targeted to its habitat, for instance sub-mediterranean species of birds and invertebrates (e.g. butterflies and acridids), which typically occur within complex habitat mosaics offering notably patches of bare ground (Schaub et al. 2010). More specifically, we addressed and discussed the following questions: (1) What are the micro-habitat associations of foraging Woodlarks? (2) What may explain their micro-habitat preferences (feeding opportunities: more food and/or better prey accessibility? (3) Could the recent increase in the area of vegetated vineyards benefit the species? (4) If yes, can we provide management guidelines for encouraging Woodlarks, and, by extension, other typical biodiversity occurring in vineyards?

\section{Materials and methods}

\section{Study site}

This study was conducted in the vineyards of Valais, which in total cover ca. $50 \mathrm{~km}^{2}$, between the communities of Vétroz $\left(46^{\circ} 13^{\prime} \mathrm{N}, 7^{\circ} 16^{\prime} \mathrm{E}\right)$ and Leuk $\left(46^{\circ} 19^{\prime} \mathrm{N}, 7^{\circ} 38^{\prime} \mathrm{E}\right)$. Based on estimates obtained from two areas surveyed in 2008 (Leytron-Chamoson and Salgesch-Leuk), the density reaches 5.3-5.9 territories per $\mathrm{km}^{2}$ (A. Sierro, unpublished data).

\section{Capture and radiotracking}

Fine-grained habitat selection patterns of foraging Woodlarks were assessed using radiotracking ( $n=7$ individuals). This technique was preferred to visual observations in order to avoid the classic habitat-dependent detection biases inherent-and rarely accounted for-in studies of 


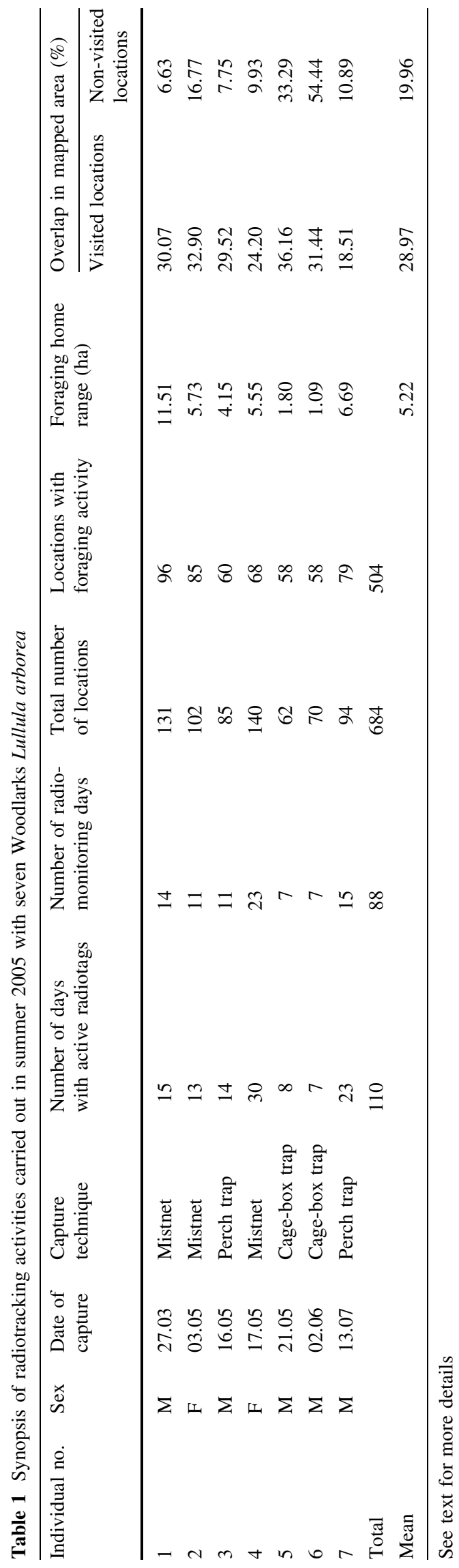

habitat selection in farmland birds (Schaub et al. 2010). All individuals were captured between March and July 2005 (Table 1). Tape-luring and stuffed birds were used to capture free-ranging birds, mostly early in the season. Capturing techniques consisted of mistnets and perch traps placed around the tape recorder and the stuffed bird. Later in the season, we also used cage-box traps positioned on the ground along the path walked by parents when feeding the chicks at the nest. Birds were ringed and sexed on the basis of the form of the cloacal protuberance, and the presence or absence of a brood patch. Radio tags (BD-2 transmitters, weight: $0.90 \mathrm{~g}$; Holohil Systems, Canada) were attached to the birds' back, with a self-breakable leg harness (Rappole and Tipton 1991) made up of thin elastic cord. The weight of the transmitters was $<3.5 \%$ of body mass (Aldridge and Brigham 1988).

The birds were first located by homing-in on the animal to get an approximate position. They were then searchedfo $r$ visually with binoculars to assess foraging activity. As the vine vegetation is rather homogeneous across the vineyards, the probability of detection was probably not affected by vegetation density. Localizations took place every $15 \mathrm{~min}$ in the case of continuous foraging in a given part of the home range, but time was reset at every major movement of the bird (i.e. flight over more than ca. $20 \mathrm{~m}$ ) and at every chick provisioning event. Only proven foraging locations were used for micro-habitat selection analyses; they were marked in the field with a numbered, coloured Scotch tape label placed directly on vineyard sticks or wires. The exact position was retrieved after the radiotracking session using a Global Positioning System (GPS).

Habitat mapping and data analysis

Individual home ranges were estimated as $100 \%$ minimum convex polygons (MCP; Animal Movement module, ArcView GIS 3.3) from ascertained foraging locations. Georeferenced maps $(1: 10,000)$ derived from the Valais land survey were fitted to a geographical information system (GIS). A buffer zone of $5 \mathrm{~m}$ was added around the $100 \%$ MCP. Micro-habitat selection was investigated by comparing habitat characteristics mapped within a $5 \mathrm{~m}$ radius around ascertained foraging locations (hereafter visited locations) with those assessed around a similar number of non-visited locations. Non-visited locations were selected randomly within the individual MCPs but with a minimum distance of $10 \mathrm{~m}$ to the foraging locations in order to exclude spatial overlaps between the two categories. Since the birds frequently returned to previously visited sites, and thus the circular surfaces around the foraging locations overlapped, non-visited locations were also allowed to overlap, with the mean proportion of overlap being in general not higher than in the visited locations (Table 1, 
Table 2 Variables recorded from field surveys at visited locations (radiotracking) and non-visited (random) locations, which describe vineyard management (1-3), ground vegetation and litter covers (4-6), and landscape elements and infrastructure (7-9)

\begin{tabular}{|c|c|c|}
\hline No. & Variable & Definition (unit) \\
\hline 1 & Vineyard age & Estimated relative age of the vineyard (diameter of main vine trunk in $\mathrm{cm}$, continuous) \\
\hline 2 & Vineyard type & Distance between plant rows: short for gobelet ${ }^{\mathrm{a}}$, large for wires; categorial, 2 levels $(0=$ gobelet, $1=$ wires $)$ \\
\hline 3 & Herbicide application & Yes or no (categorial; 2 levels: $0=$ no, $1=$ yes) \\
\hline 4 & Ground vegetation cover & Percentage of ground vegetation cover (vines not considered; continuous) \\
\hline 5 & Ground vegetation height & Mean height of grass sward (cm; continuous) \\
\hline 6 & Organic litter ${ }^{\mathrm{b}}$ & Percent coverage of organic litter on the ground (continuous) \\
\hline 7 & Wall & Presence/absence of stone or beton wall (categorial; 2 levels: $0=$ absence, $1=$ presence) \\
\hline 8 & Scrub $^{c}$ & Presence/absence of scrub (categorial; 2 levels: $0=$ absence, $1=$ presence) \\
\hline 9 & Road & Presence/absence of road (categorial; 2 levels: $0=$ absence, $1=$ presence) \\
\hline
\end{tabular}

${ }^{\text {a }}$ Gobelet is a special arrangement of vine plants, which grow small and are not arranged around wires. Gobelet is the conventional mode, compared to vines supported by wires bent between poles. In gobelet vineyards, the plant lines are typically ca $100-110 \mathrm{~cm}$ distant, whilst the spacing in wire vineyards is $120-200 \mathrm{~cm}$

b Removed from the habitat analysis because of high correlation with ground vegetation cover

${ }^{c}$ Removed from the habitat selection analysis because of highly skewed distribution

Fig. S1). Habitat mapping was carried out during specific field surveys following radiotracking sessions. Variables considered were those potentially playing a role in microhabitat selection in Woodlarks (Table 2); for instance, leaf litter was mapped as it can influence the abundance of the invertebrate food available.

We applied a generalised linear mixed model (GLMM) with a binomial error distribution and a logit link function to analyse the occurrence of Woodlarks with respect to habitat variables. This model extends the standard logistic regression model by the inclusion of random effects (Williams 1982). In this study, a logistic GLMM with random intercept terms was considered to account for the variability among individual birds. The general form of the model is given as:

$y_{i j} \sim \operatorname{Bernoulli}\left(p_{i j}\right)$

$\log \operatorname{it}\left(p_{i j}\right)=\beta^{\prime} X_{i j}+b_{i}$

$b_{i} \sim N\left(0, \sigma^{2}\right)$

where $p_{i j}$ is the probability of occurrence at a location $j$ for bird $i ; \beta$ is a vector of coefficients; $X_{i j}$ is a design matrix of habitat predictors at a location $j$ for bird $i ; b_{i}$ is a random effect for bird $i$ and $\sigma^{2}$ is the variance between individuals.

Our dataset contained nine habitat variables (Table 2). We first assessed the correlation between continuous predictors using Spearman's correlation coefficient. To avoid collinearity, we dropped predictors if their correlation coefficient $|r|$ was $>0.7$ (Hosmer and Lemeshow 1989). We then grouped the variables into main categories: vineyard management (vineyard age, vineyard type, and herbicide application), ground vegetation (ground vegetation cover and ground vegetation height), scrub, and infrastructure (wall and roads). This categorisation enabled us to generate a set of 55 a priori biologically meaningful candidate models (Table S1). We did not include interaction terms in the model. Finally, we included the quadratic term of ground vegetation cover as a curvilinear relationship was expected regarding occurrence probability with respect to this variable (Schaub et al. 2010).

The models were fitted using the lmer function in the lme4 package (Bates and Sarkar 2005) in R.2.6.2 ( $\mathrm{R}$ Development Core Team 2008). Fitted models were then compared and ordered according to their best fit to data using the Akaike Information Criterion (AIC; Akaike 1974) and Akaike weight (Burnham and Anderson 2002).

\section{Results}

Five male and two female Woodlarks were captured and radiotracked over 88 days between March and August 2005. Home ranges (non-buffered) were, on average ( $\pm \mathrm{SD}), 5.22 \pm 3.5$ ha (range: 1.0-11.5 ha; Table 1).

In total, we obtained 684 radio locations, i.e. on average $( \pm \mathrm{SD}), 98 \pm 29$ locations per bird (range: $62-140$ ). Altogether, 74\% ( $n=504$ locations, $72 \pm 15$ per individual, range: 58-96) were proven foraging locations, i.e. locations at which foraging could be assessed (Table 1).

As there was a strong negative correlation between ground vegetation cover and amount of organic litter (Spearman's correlation coefficient $=-0.73$ ), only ground vegetation cover was considered in subsequent models. In addition, the scrub predictor was removed from any analysis as $97 \%$ of the values were equal to zero. The results of GLMM analyses showed that one model (model 4) received substantial support from the data as it had a $90 \%$ likelihood of being the best model in the set of models considered. This model included the following variables: vineyard type and age, herbicide application, ground 
Table 3 The top five GLMM models ${ }^{a}$ describing the occurrence of Woodlarks based on Akaike's Information Criterion (AIC)

\begin{tabular}{|c|c|c|c|c|c|}
\hline $\begin{array}{l}\text { Model } \\
\text { no. }\end{array}$ & Variables & Deviance & $\mathrm{K}$ & $\Delta \mathrm{AIC}$ & $\begin{array}{l}\text { Akaike } \\
\text { weight }\end{array}$ \\
\hline 4 & $\begin{array}{l}\text { Vineyard age }+ \text { vineyard type }+ \text { herbicide }+ \text { ground vegetation cover }+ \text { (ground vegetation } \\
\text { cover })^{2}+\text { vegetation height }+ \text { wall }+ \text { road }\end{array}$ & $1,022.069$ & 10 & 0.000 & 0.896 \\
\hline 55 & $\begin{array}{l}\text { Vineyard age }+ \text { vineyard type }+ \text { herbicide }+ \text { ground vegetation cover }+ \text { (ground vegetation } \\
\text { cover })^{2}+\text { vegetation height }+ \text { road }\end{array}$ & $1,029.697$ & 9 & 5.628 & 0.054 \\
\hline 28 & $\begin{array}{l}\text { Vineyard type }+ \text { herbicide }+ \text { ground vegetation cover }+ \text { (ground vegetation } \\
\text { cover })^{2}+\text { vegetation height }+ \text { wall }+ \text { road }\end{array}$ & $1,030.933$ & 9 & 6.864 & 0.029 \\
\hline 46 & $\begin{array}{l}\text { Vineyard age }+ \text { vineyard type }+ \text { herbicide }+ \text { ground vegetation cover }+ \text { (ground vegetation } \\
\text { cover })^{2}+\text { wall }+ \text { road }\end{array}$ & $1,031.606$ & 9 & 7.537 & 0.021 \\
\hline 51 & $\begin{array}{l}\text { Vineyard age }+ \text { vineyard type }+ \text { herbicide }+ \text { ground vegetation cover }+ \text { (ground vegetation } \\
\text { cover })^{2}+\text { vegetation height }+ \text { wall }\end{array}$ & $1,038.547$ & 9 & 14.479 & 0.001 \\
\hline
\end{tabular}

For each model, the values for deviance, the number of estimated parameters $(K)$, the difference of the AIC between that model and the best model $(\triangle A I C)$, and the Akaike weight are shown. For model list, see Supporting Information Table S1

${ }^{\text {a }}$ The remaining 50 models had close to zero Akaike weight $(<0.001)$

Fig. 1 The populationaveraged occurrence probability of Woodlarks Lullula arborea in relation to a relative vineyard age, $\mathbf{b}$ ground vegetation height, c vineyard type, $\mathbf{d}$ herbicide application, e presence of wall and $\mathbf{f}$ presence of roads estimated from the best model (no. 4; Table 3). Vertical bars indicate $95 \%$ credible intervals, while $x$-axis boundaries correspond to the range of observed values

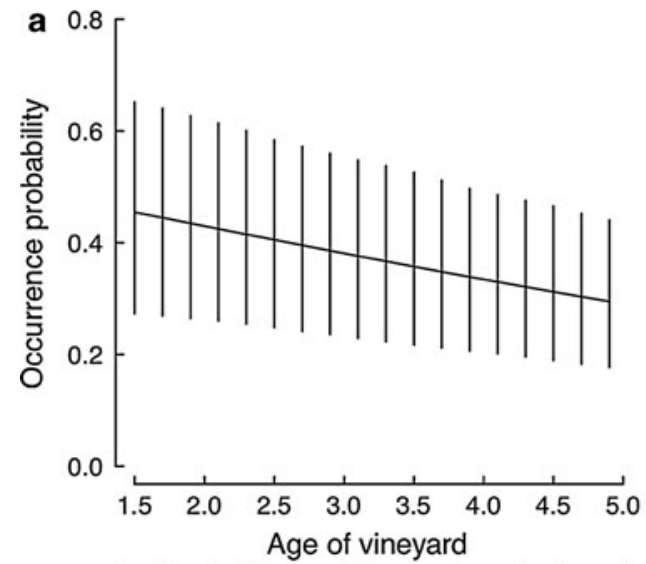

(estimated through trunk diameter in $\mathrm{cm}$ )

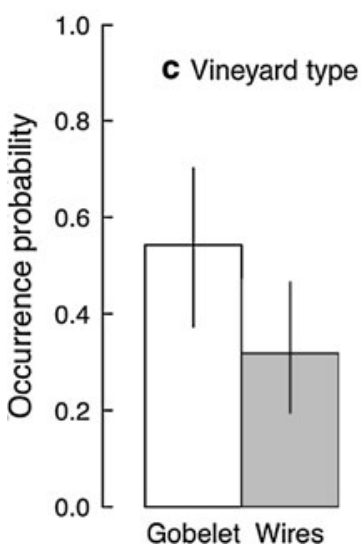

vegetation cover and its quadratic term, vegetation height, presence of walls and roads. It was $16.6(0.896 / 0.054)$ times more likely than the next best model (model 55). Vineyard management influenced Woodlark occurrence (Table 3). First, vineyard age had a negative impact (Fig. 1a); second, Woodlarks had a higher probability of occurrence in traditional "gobelet" vineyards (plants

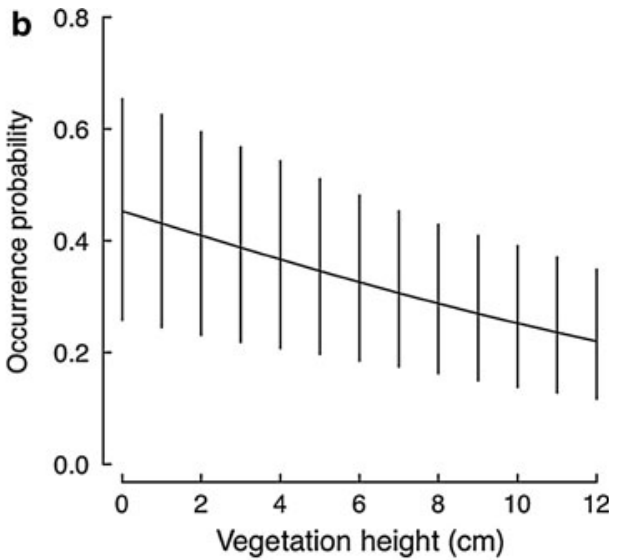

e Wall

f Road
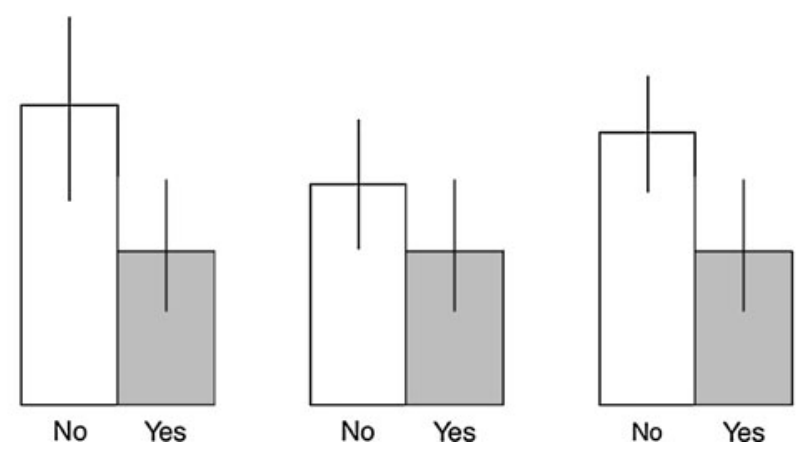

branching low above the ground and arranged in $100-110 \mathrm{~cm}$ distant rows) than in modern plantations on wires (120-200 cm distant plantation lines; Table 2; Fig. 1c); third, herbicide application negatively affected occurrence probability (Fig. 1d). Moreover, occurrence probability was strongly affected by ground vegetation: it was higher in vineyards with short ground vegetation 

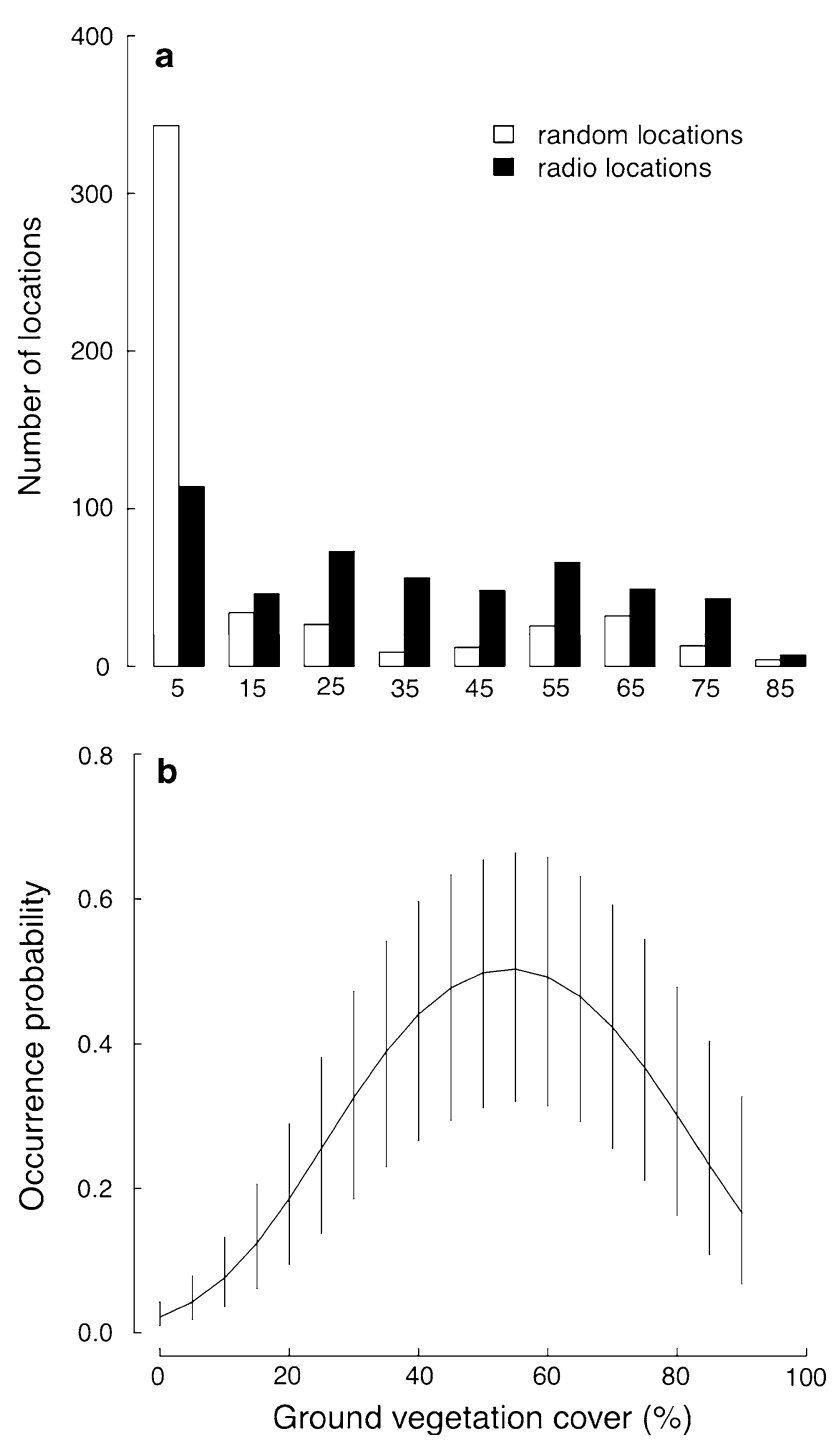

Fig. 2 a Frequency distribution of radiolocations and random locations within Woodlark home ranges: note the high proportion of random locations with ground vegetation cover of $0 \%$, which shows the predominance of "mineral" vineyards (systematic herbicide application) in birds' home ranges. b The population-averaged occurrence probability is shown in relation to ground vegetation cover, while other continuous variables are kept fixed at their average values and categorical variables are set at their last level based on our coding (see Table 2). Approximate 95\% confidence intervals were constructed by simulation

(Fig. 1b), with an optimum for species occurrence probability coinciding with ground vegetation cover around $45-60 \%$, peaking at $55 \%$ (Fig. 2). Finally, infrastructure also played a role, with the presence of walls and roads negatively impacting occurrence probability (Fig. 1e, f).

To visualise effect sizes, we calculated the predicted occurrence probability on the logit scale using the best model via simulation (Gelman and Hill 2007). In brief, we first obtained 1,000 simulations from the joint posterior distribution of the fixed effect coefficients of the best
Table 4 Estimated coefficients, and standard errors for the variables of the most parsimonious model (model 4)

\begin{tabular}{lrl}
\hline Parameter & Estimate & SE \\
\hline Intercept & 1.6438 & 0.5394 \\
Vineyard age & -0.2111 & 0.0780 \\
Vineyard type (wire) & -0.9747 & 0.2295 \\
Vegetation height & -0.0907 & 0.0286 \\
Ground vegetation cover & 0.1411 & 0.0125 \\
(Ground vegetation cover) $^{2}$ & -0.0013 & 0.0001 \\
Herbicide & -1.2952 & 0.3087 \\
Wall (presence) & -0.6029 & 0.2298 \\
Road (presence) & -1.0505 & 0.2804 \\
\hline
\end{tabular}

model. We then derived the predicted values for each of the 1,000 simulated sets of model parameters and used their mean and 2.5 and $97.5 \%$ quantiles, respectively, as predicted values with $95 \%$ credible intervals. For each predictor variable in turn, we used the lowest and the highest observed values, and calculated the occurrence probabilities while keeping the other continuous predictor variables at their means and the categorical variables at their last level based on our coding (see Table 2). A greater change between the maximum and minimum predicted values was observed for ground vegetation cover (3.819), followed by herbicide application (1.296), vegetation height (1.086), roads (1.057), vineyard type (0.968), vineyard age (0.706), and walls (0.601) (Table 4). These results provide evidence for the outstanding role of ground vegetation cover in patterns of micro-habitat selection by Woodlarks.

\section{Discussion}

Our results support the hypothesis that new methods of vine cultivation may be beneficial to terrestrially foraging insectivorous vertebrates, as illustrated here by the Woodlark in southern Switzerland. It was primarily the proportion of ground vegetation cover that influenced the pattern of micro-habitat selection. The importance of bare ground for Woodlarks has also been established for intensively managed forests and heathland in the UK (reviewed in Langston et al. 2007). Conventional, mineral vineyards, where herbicides are applied over the entire soil surface, still predominate in Valais, representing $\geq 95 \%$ of the area devoted to this culture (Sierro and Arlettaz 2003). This situation is recognizable even within our studied Woodlark home ranges: $69 \%$ of the random locations (which roughly mirror availability) fell within a ground vegetation cover below $10 \%$ (Fig. 2a). If the availability of mineral vineyards is generally higher in our study area as a whole than in Woodlark home ranges, it is because the 
radiotracked birds already operated a macro-scale habitat selection towards areas presenting a higher proportion of vegetated vineyards than average. Occurrence probability declined strongly when ground vegetation cover was below $20 \%$; thus the application of herbicides impacted microhabitat selection negatively. It also declined noticeably when ground vegetation cover was more than $80 \%$ (Fig. 2a). This defines an optimum for ground vegetation cover at around $45-60 \%$ (peaking at ca. 55\%). A similar optimum was obtained by Schaub et al. (2010). These authors studied several insectivorous bird species (including Woodlarks) occurring in different farmland habitat types, but used a different analytical framework: they estimated the optimal proportion of bare ground, not ground vegetation as here, at the foraging site scale. Finally, similar proportions of ground vegetation were obtained for Woodlarks in heathland and rejuvenating forests in the UK (optimum around $43 \%$ bare ground; Langston et al. 2007; Mallord et al. 2007) and skylarks in Germany (35-60\%; Toepfer and Stubbe 2001). Hence, Woodlarks prefer vegetated vineyards insofar as they offer a mosaic of grass and herbs interspersed with bare surfaces, the former providing food supply and nesting opportunities, the latter foraging grounds.

The age of vineyards had a negative effect on Woodlark occurrence, which may be explained by the fact that young vineyards offer a less dense vine canopy than old vineyards. As the Woodlark is predominantly a species of open and semi-open landscapes, the dense vine canopy of older vineyards may deter the birds. Moreover, herbicide application is less intensive in young vineyards to avoid inadvertently damaging the fragile growing vines. A preference for the traditional "gobelet" vineyards compared to the "wire" vineyard type may indicate that the latter does not automatically offer suitable habitat conditions, despite a greater height of the vine plants above the ground and a greater distance between the plants (Table 2). Ground vegetation management thus appears to be more important than vine vegetation configuration. Similar findings have been obtained in coniferous plantations in the UK, where occupancy by Woodlarks peaks in compartments aged 1-3 years, declining until 6-7 years, after which the land becomes generally unsuitable due to the growing field layer. However, older forestry compartments can remain suitable if the ground layer is managed sympathetically (Langston et al. 2007). Finally, short vegetation also increases occurrence probability, as already established for other species of birds (e.g. Boatman et al. 2004).

These elements confirm the conclusions of previous work about the importance of food accessibility for terrestrial insectivorous birds inhabiting grassland (Atkinson et al. 2004, 2005; Butler and Gillings 2004; McCracken and Tallowin 2004). Nevertheless, the Woodlark in Valais vineyards represents a totally different situation than that for other grassland bird species in general and even for British Woodlarks in particular (Langston et al. 2007, Mallord et al. 2007). This is because the predominant habitat conditions in the Valais study area are not a too-dense grass vegetation cover, unlike in all other studies on micro-habitat selection of farmland birds, but a predominantly bare habitat $(\geq 95 \%$ of mineral vineyards). Thus, although extensifying agricultural practices in grassland production will positively affect bird population dynamics (Hansen and Urban 1992; Benton et al. 2002; Britschgi et al. 2006; Schaub et al. 2010), in the case of Woodlarks inhabiting vineyards, it is the promotion of more vegetation on the ground which supports the species: if ground vegetation is absent, then food supply remains insufficient, especially as regards arthropods which constitute the staple food of Woodlarks during reproduction. Genini (2000) showed that grounddwelling arthropods such as spiders, carabid beetles, ants and locusts have more diverse communities and more abundant populations in vegetated vineyards.

Finally, the probability of the occurrence of foraging Woodlarks decreases with increasing infrastructure such as walls and roads. At a regional scale, Woodlarks prefer the shallow vineyard plateaux rather than the steep slopes arranged in terraces separated by numerous stone walls (Sierro and Arlettaz 2003). The negative effect of roads could indicate an avoidance of traffic or human disturbance, as demonstrated in the UK (Mallord et al. 2007).

Conventional vine cultivation practices that systematically rely on herbicides create an entirely mineral, i.e. hostile, habitat matrix for Woodlarks in southern Europe. A progressive switch to new cultivation practices such as biological control (integrated production) and organic production seems thus to be beneficial for the Woodlark in particular and for biodiversity in general. At the other end of the management spectrum, however, organic vineyards, which mostly have a continuous and dense ground vegetation cover because herbicides are prohibited, hamper the accessibility to food resources for the Woodlark, and probably also for many other species feeding on the ground (Schaub et al. 2010). Organic wine producers should thus envisage maintaining bare ground surfaces by regularly removing part of the ground vegetation mechanically (optimally on about half the surface at the foraging site scale). Currently, the best practice seems to be the biological control protocol (integrated production), but only provided that ground vegetation is tolerated. The rare wine producers achieving the optimal trade-off typically treat every second row with herbicides, which provides the ideal $50 \%$ ground vegetation cover described above. Unfortunately, it is still the case that too few wine producers adopt this practice. If the scheme spread, wine producers would encourage the survival of a vulnerable, emblematic species 
of bird, as well as other wildlife typical of arid, semi-open cultivated landscapes of southern Europe.

Acknowledgments We thank A. Morgenthaler, N. Signorell, R. Spaar, B. Naef-Daenzer, A. Sierro, S. Wirthner and P. Patthey for field and computer assistance. S. Seiler-Lyons and J. Zbinden corrected an early version of the manuscript. R. Oggier provided us with free georeferenced maps of the study areas. P. Constantin, B. Michellod and A. Montani provided information about vineyard cultivation. Thanks to all viniculturists who provided free access to their ground. A. Gerber, H. Schmid and A. Sierro provided information about population size estimates. Fränzi Korner and an anonymous reviewer greatly improved the manuscript. This study was supported by a grant of the Foundation Dr Ignace Mariétan (La Murithienne, Société Valaisanne de Sciences Naturelles).

\section{References}

Akaike H (1974) A new look at the statistical model indentification. IEEE Trans Autom Control 19:716-722

Aldridge HDJN, Brigham RM (1988) Load carrying and maneuverability in an insectivorous bat: a test of the $5 \%$ "rule" of radiotelemetry. J Mammal 69:379-382

Atkinson PW, Buckingham D, Morris AJ (2004) What factors determine where invertebrate-feeding birds forage in dry agricultural grasslands? Ibis 146(Suppl. 2):99-107

Atkinson PW, Fuller RJ, Vickery JA, Conway GJ, Tallowin JRB, Smith REN, Haysom KA, Ings TC, Asteraki EJ, Brown VK (2005) Influence of agricultural management, sward structure and food resources on grassland field use by birds in lowland England. J Appl Ecol 42:932-942

Bates DM, Sarkar D (2005) 1me4: Linear mixed-effects models using S4 classes. R package version 0:9975-9977

Benton TG, Bryant DM, Cole L, Crick HQP (2002) Linking agricultural practice to insect and bird populations: a historical study over three decades. J Appl Ecol 39:673-687

Benton TG, Vickery JA, Wilson JD (2003) Farmland biodiversity: is habitat heterogeneity the key? Trends Ecol Evol 18:182-188

Boatman ND, Brickle NW, Hart JD, Milsom TP, Morris AJ, Murray AWA, Murray KA, Robertson PA (2004) Evidence of the indirect effects of pesticides on farmland birds. Ibis 146(Suppl. 2):131-143

Brickle NW, Harper DGC, Aebischer NJ, Cockayne SH (2000) Effects of agricultural intensification on the breeding success of corn buntings Miliaria calandra. J Appl Ecol 37:742-755

Britschgi A, Spaar R, Arlettaz R (2006) Impact of grassland farming intensification on the breeding ecology of an indicator insectivorous passerine, the whinchat Saxicola rubetra: Lessons for overall Alpine meadowland management. Biol Conserv 130:193-205

Burfield I, van Bommel F (2004) Birds in Europe: populations estimates, trends and conservation status. Birdlife International, Cambridge

Burnham KP, Anderson DR (2002) Model selection and multimodel inference: a practical information-theoretic approach. Springer, New York

Butler SJ, Gillings S (2004) Quantifying the effects of habitat structure on prey detectability and accessibility to farmland birds. Ibis 146(Suppl. 2):123-130

Donald PF, Green RE, Heath MF (2001) Agricultural intensification and the collapse of Europe's farmland bird populations. Proc R Soc Lond B 268:25-29
Gelman A, Hill J (2007) Data analysis using regression and multilevel/hierarchical models. Cambridge University Press, New York

Genini M (2000) Faune épigée de la vigne et des milieux environnants. Rev Suisse Vitic Arboric Hortic 32:1-12

Glutz von Blotzheim UN, Bauer KM (1985) Lullula arborea (Linnaeus 1758)-Heidelerche. In: Glutz von Blotzheim UN (ed) Handbuch der Vögel Mitteleuropas. Band 10/I Passeriformes (1.Teil) Alaudidae-Hirundinidae. AULA-Verlag, Wiesbaden, pp 188-228

Gregory RD, Noble DG, Custance J (2004) The state of play of farmland birds: population trends and conservation status of lowland farmland birds in the United Kingdom. Ibis 146(Suppl. 2): $1-13$

Hansen AJ, Urban DL (1992) Avian response to landscape pattern: the role of species' life histories. Landsc Ecol 7:163-180

Hole DG, Perkins AJ, Wilson JD, Alexander IH, Grice PV, Evans AD (2005) Does organic farming benefit biodiversity? Biol Conserv 122:113-130

Hosmer DW Jr, Lemeshow S (1989) Applied logistic regression. Wiley, New York

Keller V, Ayé R, Müller W, Spaar R, Zbinden N (2010a) Die prioritären Vogelwarten der Schweiz: Revision 2010. Ornithol Beob 107:265-285

Keller V, Gerber A, Schmid H, Volet B, Zbinden N (2010b) Rote Liste Brutvögel. Gefährdete Arten der Schweiz. Stand 2010. Umweltvollzug Nr 1091. Bundesamt für Umwelt BAFU, Bern and Schweizerische Vogelwarte, Sempach

Langston RHW, Wotton SR, Conway GJ, Wright LJ, Mallord JW, Currie FA, Drewitt AL, Grice PV, Hoccom DG, Symes N (2007) Nightjar Caprimulgus europaeus and woodlark Lullula arborearecovering species in Britain? Ibis 149(Suppl. 2):250-260

Leuzinger H (1955) Zum Brüten der Heidelerche in der Kulturlandschaft des Mittellandes. Ornithol Beob 52:77-82

Mallord JW, Dolman PM, Brown AF, Sutherland WJ (2007) Linking recreational disturbance to population size in a ground-nesting passerine. J Appl Ecol 44:185-195

Martinez N, Jenni L, Wyss E, Zbinden N (2010) Habitat structure versus food abundance: the importance of sparse vegetation for the common redstart Phoenicurus phoenicurus. J Ornithol 151:297-307

McCracken DI, Tallowin JR (2004) Swards and structure: the interactions between farming practices and bird food resources in lowland grasslands. Ibis 146(Suppl. 2):108-114

Poulsen JG, Sotherton NW, Aebischer NJ (1998) Comparative nesting and feeding ecology of skylarks Alauda arvensis on arable farmland in southern England with special reference to set-aside. J Appl Ecol 35:131-147

R Development Core Team (2008) R: a language and environment for statistical computing. R Foundation for Statistical Computing, Vienna

Rappole JH, Tipton AR (1991) New harness design for attachment of radio transmitters to small passerines. J Field Ornithol 62:335-337

Schaub M, Martinez N, Tagmann-Ioset A, Weisshaupt N, Maurer ML, Reichlin TS, Abadi F, Zbinden N, Jenni L, Arlettaz R (2010) Patches of bare ground as a staple commodity for declining ground-foraging insectivorous farmland birds. PLoS ONE 5:e13115

Schmid H, Luder R, Naef-Daenzer B, Graf R, Zbinden N (1998) Schweizer Brutvogelatlas. Verbreitung der Brutvögel in der Schweiz und im Fürstentum Liechtenstein 1993-1996. Schweizerische Vogelwarte, Sempach

Schmid H, Burkhardt M, Keller V, Knaus P, Volet B, Zbinden N (2001) Die Entwicklung der Vogelwelt in der Schweiz. Avifauna Report Sempach. Schweizerische Vogelwarte, Sempach 
Sierro A, Arlettaz R (2003) L'avifaune du vignoble en Valais central: évaluation de la diversité à l'aide de transects. Nos Oiseaux 50:89-100

Snow DW, Perrins CM (eds) (1998) The Birds of the Western Palearctic. Vol 2: Passerines. Concise Edn. Oxford University Press, Oxford

Toepfer S, Stubbe M (2001) Territory density of the Skylark (Alauda arvensis) in relation to field vegetation in central Germany. J Ornithol 142:184-194

Verhulst J, Báldi A, Kleijn D (2004) Relationship between land-use intensity and species richness and abundance of birds in Hungary. Agric Ecosyst Environ 104:465-473

Vickery JA, Tallowin JR, Feber RE, Asteraki EJ, Atkinson PW, Fuller RJ, Brown VK (2001) The management of lowland neutral grasslands in Britain: effects of agricultural practices on birds and their food resources. J Appl Ecol 38:647-664
Weisshaupt N, Arlettaz R, Reichlin TS, Tagmann-Ioset A, Schaub M (2011) Habitat selectin by foraging Wrynecks Jynx torquilla during the breeding season: identifying the optimal habitat profile. Bird Study 58:111-119

Wickramasinghe LP, Harris S, Jones G, Vaughan N (2003) Bat activity and species richness on organic and conventional farms: impact of agricultural intensification. J Appl Ecol 40:984-993

Williams DA (1982) Extra-binomial variation in logistic linear models. J R Stat Soc C (Appl Stat) 31:144-148

Wright JL, Hoblyn RA, Green RE, Bowden CFG, Mallord JW, Sutherland WJ, Dolman PM (2009) Importance of climatic and environmental change in the demography of a multi-brooded passerine, the woodlark, Lullula arborea. J Appl Ecol 78:1191-1202 